\title{
A review on the state of knowledge, conceptual and theoretical contentions of major theories and principles governing groundwater flow modeling
}

\author{
Kassim Ramadhani Mussa ${ }^{1,2} \cdot$ Ibrahimu Chikira Mjemah² $\cdot$ Alfred Nzibavuga Nyarubakula Muzuka
}

Received: 12 August 2019 / Accepted: 7 April 2020 / Published online: 26 May 2020

(c) The Author(s) 2020

\begin{abstract}
Decision-makers require correct and adequate information on groundwater flow systems in a basin in order to formulate sustainable water resources development strategies. However, the practicality and realism of groundwater flow system models depend on the validity, reliability and availability of quality data and information, and how they are used in model development and calibration. This goes hand in hand with how the underlying theories, tenets and assumptions are understood, interpreted and applied. The more uncertain and contentious the information is, the wider are the knowledge and theoretical gaps, and thus the less useful the model results are for decision-making. The understanding of water table types in groundwater basins has become one of the additional factors for an in-depth understanding and modeling of nested groundwater flow systems. The classification of water table types using a water table ratio provides that if the ratio is more than 1 , this depicts a topography-controlled area and a ratio of less than 1 depicts a recharge-controlled terrain. Log transformation of the water table ratio proved the same interpretation. This paper therefore reviews the evolution of groundwater flow systems theory, the prevailing knowledge and theoretical gaps by specifically pinpointing the theoretical and conceptual contentions and additional factors which can possibly limit the application of groundwater flow theories in regional groundwater modeling studies. The implications of how the conceptual and theoretical contentions affect groundwater modeling for decision-making in groundwater development and management are also pinpointed in this paper.
\end{abstract}

Keywords State of knowledge $\cdot$ Conceptual and theoretical contentions · Contemporary applications · Groundwater flow modeling

\section{Background information}

The interest of modeling nested groundwater flow systems has grown rapidly over the last decade (Havril et al. 2017). The application of numerical simulations to identify organization, pattern, hierarchy and controls on different types of groundwater flow systems in two- and three-dimensional models is increasingly becoming useful to evaluate potential groundwater management strategies and to simulate

Kassim Ramadhani Mussa

kassimr@gmail.com

1 School of Materials, Energy, Water and Environmental Sciences, Nelson Mandela African Institution of Science and Technology, P.O. Box 447, Arusha, Tanzania

2 Department of Geography and Environmental Studies, Sokoine University of Agriculture (SUA), P.O. Box 3038, Morogoro, Tanzania groundwater budget component changes with time in large complex basins. This approach is also used for optimizing groundwater development scenarios (Zhou and Li 2011). Acceptably, groundwater flow systems modeling is equally important for exploring options for sustainable groundwater resources management. With the use of groundwater flow models therefore, the effects of climatic and non-climatic factors on groundwater availability and balance can be accurately predicted. Numerical flow modeling replaces to a large extent the analytical approach.

However, owing to frequent and erratic changes, decisionmakers require updated, adequate and correct information on groundwater flow systems in a basin in order to formulate sustainable water resources development strategies. Thus, research on groundwater flow systems, including their characterization as a function of internal and external processes, is of great importance for enhancing conceptualization of groundwater flow systems and to improve the understanding 
of groundwater flow hierarchy, patterns and organization (Huizar-Alvarez et al. 2016). This also serves to improve numerical groundwater modeling. To that effect, there is an extensive use of the groundwater flow theories owing to a paradigm shift from a mere understanding of the groundwater basin characterized by local flow systems, and aerial recharge as the main water input mechanism, rather taking groundwater basin as a function of nested groundwater flow systems affected by climate, geology, topography and groundwater basin geometry.

Therefore, the appropriateness and practicality of the groundwater flow system models hugely depend on the availability, validity and reliability of quality data and information, and how they are used in model development and calibration. This also depends on how the underlying theories, principles, tenets and assumptions are conceptualized, understood and interpreted. The more uncertain and contentious the information is, the wider are the knowledge, conceptual and theoretical gaps, and thus the less reliable the model results are to decision and policymakers. Nevertheless, there exist feeble and inadequate assessment of the state of knowledge, theoretical and conceptual contentions on the major theories and principles governing groundwater flow modeling and how this affects the ensuing modeling results and their application. Equally so, the assessment on how relevant some of these theories are in the contemporary applications in numerical groundwater flow modeling is hugely scanty. This is irrespective of the fast-growing utilization of numerical groundwater flow models to inform policy and decision-making around the world.

This work therefore reviews the evolution of groundwater flow systems theory, the prevailing knowledge and theoretical gaps. This review paper also sought to pinpoint the theoretical and conceptual contentions, highlighting on how the scientific, conceptual and theoretical contentions limit the application of groundwater flow theories. Moreover, the implications of how the conceptual and theoretical contentions affect groundwater flow modeling for decision-making in groundwater development and management are identified in this paper. Just like what has been done previously by other researchers in other fields (e.g., Ahmaruzzaman and Gupta 2011, Gupta et al. 2013, Saleh and Gupta 2014), this review also attempts to compile relevant knowledge on the prominent groundwater flow theories, their application and limitations, taking into account the evolution of new knowledge in the field.

This paper is divided into four main subsections, beginning with a review on the evolution and application of groundwater flow theories. This is followed by a succinct review of the prevailing scientific and conceptual contentions in the classification of water tables into topographycontrolled and recharge-controlled types. The state of knowledge and conceptual and scientific gaps in groundwater flow modeling are highlighted thereof in the third subsection, culminating with conclusions and brief insights on future research direction based on the observed theoretical, scientific and conceptual contentions.

\section{The evolution and application of groundwater flow theories}

The literature refers the genesis of groundwater flow theories back in the era of Toth (1962) and Toth (1963). However, Dupuit (1863) and Forchheimer (1886) are said to possibly be the first to address issues around regional groundwater flow by developing an approach for flow in unconfined aquifers bounded by a free surface. This approach was later advanced by Forchheimer (1930), which is generally grounded on the following main assumptions: (i) Flowlines are assumed to be horizontal and equipotential lines are vertical, (ii) the hydraulic gradient is assumed to be equal to the slope of the free surface, and it is invariant with depth, (iii) no vertical flow, (iv) there is a relatively flat water table, (v) under all those preceding conditions, the water table should not be perched. These assumptions combined form, what is literally known as the Dupuit-Forchheimer theory of freesurface flow.

The Dupuit-Forchheimer theory proposed to ignore the vertical flow so as to simplify the problem into one- and two-dimensional horizontal flows. By neglecting the vertical flow components, it culminates in reducing the twodimensional system to one dimension just for the sake of simplifying the analysis. In another development however, Hubbert (1940) contributed to the topic by constructing a conceptual groundwater model catering for the flow between parallel streams which also featured resistance to vertical flow borrowing some ideas from the Dupuit-Forchheimer approximation.

Nonetheless, the most prominent and contemporary theoretical artifact of regional groundwater flow systems dwells on the theoretical exposition of Toth (1962) and Toth (1963), utilizing synthetic basins, dubbed the Tothian basins. From there on, the understanding of basin-scale groundwater flow patterns has been based on Toth's findings of a single flow system in a unit basin (Toth 1962) and nested flow systems in a complex basin (Toth 1963). In the latter, local, subregional and regional groundwater flow systems are differentiated on the basis of the length of groundwater travel between recharge and discharge locations (Toth 1963). In local systems, groundwater recharges and discharges in the same drainage basin, whereas in subregional systems groundwater discharges in a drainage basin down-gradient from that in which it recharges (Toth 1963). In regional 
systems, groundwater recharges in the uppermost basin and discharges in the lowermost basin (Toth 1963).

Reportedly, Freeze and Witherspoon (1966) were possibly among the first authors to develop a steady-state regional groundwater flow model using hypothetical layered aquifer systems, applying the Tothian concepts (Zhou and Li 2011). In tandem with that, Freeze and Witherspoon (1967) determined the effect of topography and geologic structures of differing permeabilities upon groundwater flow pattern by simulating groundwater flow systems in 2D-vertical geologic cross sections under homogeneous and isotropic conditions. Notwithstanding, Vandenberg (1980) applied and improved the work of Toth (1962) by developing transient model in a unit basin and studied flow field distortion under a periodically changing water table. Additionally, Zhao et al. (2018) extended the work of Toth (1963) by deriving a transient solution under a periodically changing water table in a complex basin and examined the transient behavior of nested flow systems, which was an extended application of Vandenberg (1980) method. Nevertheless, the Tothian theories of groundwater flow in unit basin (Toth 1962) and complex basins (Toth 1963) in most cases assume that water table is always a subdued replica of topography (Haitjema and Mitchell-Bruker 2005).

Haitjema and Mitchell-Bruker (2005) pointed out that the theories of Toth and Dupuit-Forchheimer, which are seemingly the two prominent theories on groundwater flow, are somehow contradicting. Toth (1963) apprehends both horizontal and vertical flow components in the nested flow systems while the Dupuit-Forchheimer theory ignores the vertical flow component especially on the regional flow. Despite all this, the literature is vehemently silent on the take of Dupuit-Forchheimer theory on the vertical components in local and intermediate flows. Moreover, Haitjema and Mitchell-Bruker (2005) demonstrated that the Dupuit-Forchheimer approximation is applicable in areas where there are usable aquifers. The classification of usable and non-usable aquifers has been provided by Haitjema and Mitchell-Bruker (2005) and is critically discussed in the subsequent subsections. Hitherto, it suffices to say that the fact that the Dupuit-Forchheimer approximation is applicable in areas where there are usable aquifers; it implies that the Dupuit-Forchheimer approximation is applicable in recharge-controlled water table areas. This argument is still scientifically hovering and needs further investigation since the concepts and tenets behind the classification of water tables into topography-controlled and recharge-controlled are still scientifically contentious as it is discussed later in this paper. Moreover, despite some agreements between Tothian and Dupuit-Forchheimer theories, there is a scientific caveat that the Dupuit-Forchheimer approximation is mainly applicable when the distance between hydrological boundaries is comparatively larger than the effective aquifer thickness (Haitjema and Mitchell-Bruker 2005). Furthermore, anisotropy invalidates the Dupuit-Forchheimer approximation by affecting groundwater mounding, remarked (Haitjema and Mitchell-Bruker 2005).

Generally, unlike the hypothetical Tothian basins, most groundwater basins are located in areas that are made up of diverse hydrologic and geologic landscapes, having distinctive 3D features (Welch and Allen 2012). Worman et al. (2007, 2015) added that those environments have complex topography and geology which can result in more complex groundwater flow patterns and hierarchy. The scientific, theoretical and conceptual paradoxes behind the classification of water tables into topography-controlled and rechargecontrolled are discussed in detail in the following subsection.

\section{Scientific and conceptual contentions in the classification of water tables into topography-controlled and recharge-controlled}

Recently, the idea of distinguishing water table types has been thought of being imperative for studying how regional groundwater flow systems are conceptualized and understood (Gleeson et al. 2011). Therefore, any scientific and conceptual contentions in the classification and subsequently mapping of water tables at any scale have a huge implication on studying, understanding and modeling of groundwater flow systems. This has not been explored much and the reviews on this subject are hugely inadequate if not missing at all. According to Haitjema and Mitchell-Bruker (2005) and Gleeson et al. (2011), water tables can be identified and classified distinctively into topography-controlled and recharge-controlled. In simple definition, the former closely mimics topography while the latter is particularly disconnected from the topography.

Toth (1963) and other subsequent works (e.g., Haitjema and Mitchell-Bruker 2005; Gleeson et al. 2011) discovered that in regions with recharge-controlled water tables, which, according to Haitjema and Mitchell-Bruker (2005) are found in dry and high-permeability terrains, regional groundwater flow makes up to $60 \%$ of the watershed budget. In contrast, regions with topography-controlled water tables, which are said to be found in humid areas with low-permeability terrains, have less than $10 \%$ of the watershed budget coming from regional groundwater flow (Haitjema and MitchellBruker 2005; Gleeson et al. 2011). To further understand the distribution of water table types in a basin, Haitjema and Mitchell-Bruker (2005) introduced three simple dimensionless ratios to characterize the groundwater flow regimes, which are (i) the recharge $(R)$ over hydraulic conductivity $(k),(R / k)$; (ii) the distance between hydrological boundaries $(L)$ over the saturated aquifer thickness $(H),(L / H)$; and (iii)

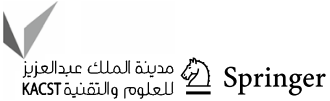


the distance between hydrological boundaries over the maximum terrain rise $(d)(L / d)$. It is argued here that of these, the $R / k$ ratio is the most useful and applicable, taking into account the two water table types. The other ratios are somehow biased towards topography-controlled basins, which are seemingly humid, and the interaction between surface and groundwater is conspicuous unlike in dry climates characterized by recharge-controlled water table. On top of that, the water table classification by Haitjema and Mitchell-Bruker (2005) misses out on areas that are dry with low permeability and those that are humid with high aquifer permeabilities. In addition to that, fractured aquifer systems are missing out in the exposition of Haitjema and Mitchell-Bruker (2005).

Moreover, recharge-controlled and topography-controlled water tables can be differentiated using a dimensionless criterion, the water table ratio (WTR) as shown in Eq. 1. Based on the assumptions of the Dupuit-Forchheimer approximation, the WTR is an extended application of the Dupuit-Forchheimer theory, which is only valid if the investigation of water table types is carried out either at a regional or continental scale.

$\mathrm{WTR}=\frac{R L^{2}}{m k H d}=\left(\begin{array}{l}>1 \\ <1\end{array}\right)$,

where $R$ is recharge, $L$ is the distance between hydrological boundaries, $H$ is the saturated aquifer thickness, $k$ is hydraulic conductivity, $d$ is the maximum terrain rise, $m$ is either 8 or 16, depending on the flow problem being investigated, one-dimensional or radial symmetric, respectively.

WTR of $>1$ depicts a topography-controlled area, and a WTR of $<1$ depicts a recharge-controlled terrain (Haitjema and Mitchell-Bruker 2005). Gleeson et al. (2011) log-transformed the water table ratio, but in the interpretation the results remained the same as $-\log$ (WTR) indicates recharged-controlled, whereas while $+\log$ (WTR) depicts topography-controlled water tables. This paper reveals how important it is to study water table types in a basin using the water table ratio because it is related to water table depth and gives a good indication of the potential for nested groundwater flow systems. However, a conceptual contention arises due to that fact that it was clearly stated that $L$ has to be larger than "effective" aquifer thickness (see Eq. 2), which implies that WTR has to consider anisotropy, but in most applications, this has not been the case.

$L>\sqrt{\frac{K_{\mathrm{h}}}{K_{\mathrm{v}}}} H$,

where $K_{\mathrm{h}}$ connotes a horizontal hydraulic conductivity and $K_{\mathrm{v}}$ represents a vertical hydraulic conductivity.

To justify the said contradiction, Haitjema and MitchellBruker (2005), for example, argued that $K$ in Eq. 1 must be interpreted as horizontal hydraulic conductivity. This is a conceptual misunderstanding and a contention as well because this argument clearly emphasizes on neglecting aquifer anisotropy. Therefore, when does anisotropy become a key factor and when it does not remains a huge scientific gap. It therefore raises some scientific controversies, and thus, the validity of the ensuing results of water table type classification and mapping using WTR as the only yardstick is somehow scientifically questionable.

From Figs. 1, 2, and Eq. 1, it is clear that the water table ratio is derived from six main parameters, (i.e., $R, L, K, H, d$ and $m$ ). Therefore, it remains unclear on what exactly controls the water table type in aquifers with contrasting climate
Fig. 1 A schematic diagram depicting a topography-controlled water table (Modified from Gleeson et al. 2011)

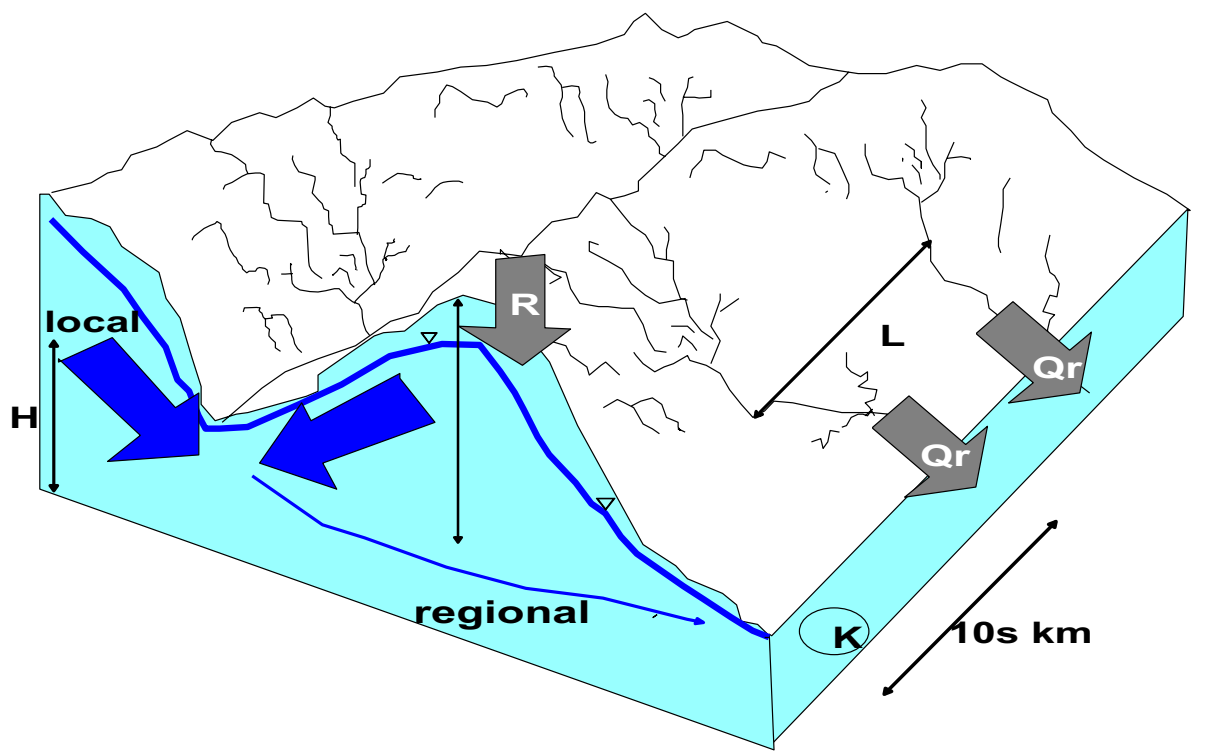


Fig. 2 A schematic diagram depicting a recharge-controlled water table ( Modified from Gleeson et al. 2011)

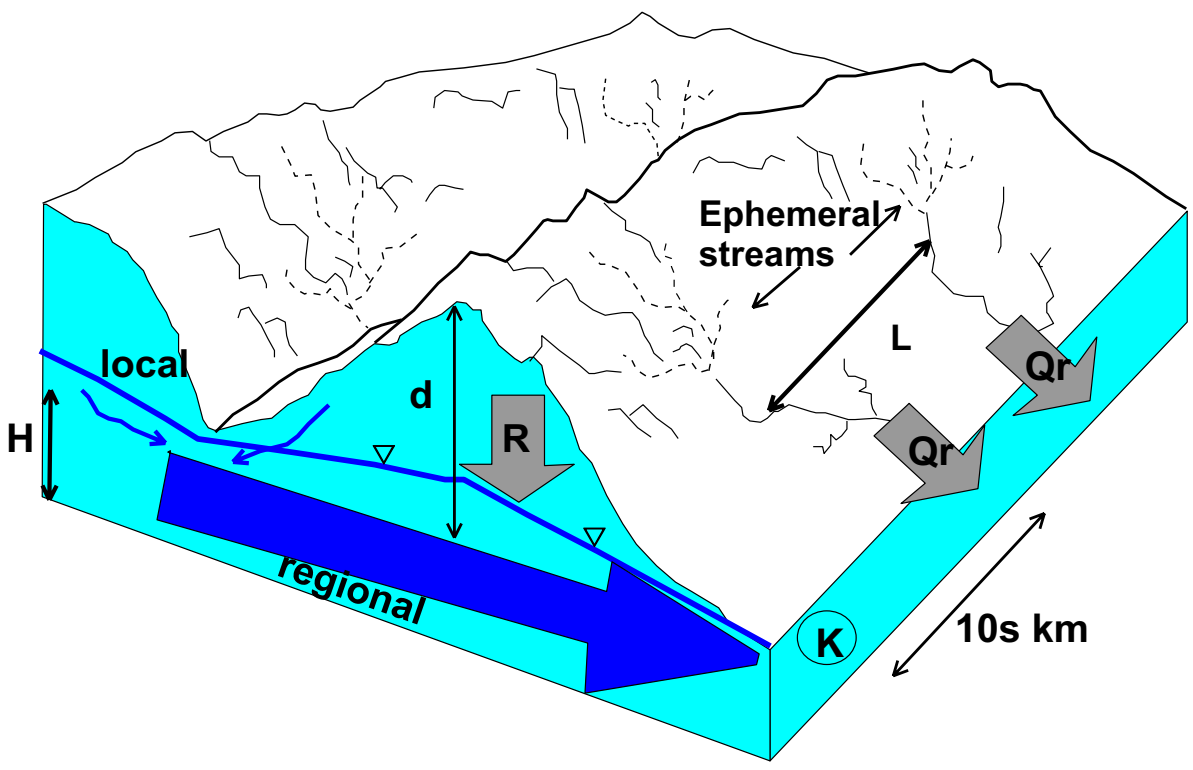

and non-climatic factors. This question was also put forward by Gleeson et al. (2011) as one of the major prevailing research gaps which remain open for further research. Furthermore, Figs. 1, 2 present the diagrammatic representation of a topography-controlled water table basin (Fig. 1) and a recharge-controlled water table basin (Fig. 2). The thickness of the blue lines indicates the importance and magnitude of the flow. The thicker the line, the more important and larger is the flow type.

Further to that, the classification of aquifers into rechargecontrolled and topography-controlled proposed by Haitjema and Mitchell-Bruker (2005) is based on a number of underlying assumptions, which are scientifically contentious too. The assumptions are as follows: (i) In topography-controlled water table (humid) terrains, potential recharge is higher than actual recharge while in areas of recharge-controlled water table potential recharge is equal to actual recharge. This is due to the fact that it is assumed that topographycontrolled water tables occur in areas of low hydraulic conductivity/permeabilities. (ii) Topography-controlled water tables occur in humid areas, and recharge-controlled water tables are found in arid/semiarid areas. (iii) In humid, topography-controlled water table areas, there are unusable aquifers due to very low hydraulic conductivities and usable aquifers are found in dry, recharge-controlled water table terrains where hydraulic conductivities are very high. However, according to Gleeson et al. (2011) in some mountainous, dry areas, low water table ratios have been reported, indicating the presence of a recharge-controlled water table while in some areas with low permeabilities, high recharge rate and moderate topography resulted in high water table ratio, which according to Haitjema and Mitchell-Bruker (2005), is a topography-controlled water table basin. This suggests that in some regions, the variables have contrasting influence. Thus, the classification and its underlying assumptions remain scientifically contentious. Consequently, their application in groundwater investigation, modeling and the ensuing decision-making can be misleading. Accordingly, Gleeson et al. (2011) remarked that the recharge-controlled water table does not necessarily connote recharge as the main controlling factor, and Haitjema and Mitchell-Bruker (2005) pointed out that the naming happened just for the sake of brevity. This implies that there could be other more important factors which define the water table types more precisely than does the WTR. Those factors are not very well known yet.

Moreover, it is assumed that local climate and land cover dynamics may not matter most in recharge-controlled water table terrains (Haitjema and Mitchell-Bruker 2005; Gleeson et al. 2011). However, it is not clearly shown how the combination of climatic and non-climatic factors is likely to affect the hierarchy, organization and pattern of groundwater flow systems in recharge-controlled and topography-controlled water table basins. Reportedly, climate change and land cover dynamics have huge and immediate effects on shallow groundwater systems (Kurylyk et al. 2015). Haitjema and Mitchell-Bruker (2005) demonstrated that the nature of the water table depends on recharge, the aquifer transmissivity (which is the product of hydraulic conductivity and saturated aquifer thickness), the aquifer geometry, and to some degree the topography. Still, it remains unclear on how future recharge will affect future nested groundwater flow systems in both topography-controlled and rechargecontrolled water table basins, and insights on where, under future climate and land cover dynamics should groundwater development be focused are equally inept.

All along it is agreed that the water table ratio is an important indicator of regional groundwater flow systems.

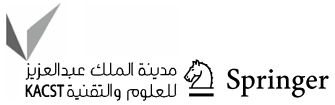


According to previous studies (Gleeson et al. 2011), the water table ratio depicted very well the relationship between the continental patterns and the ratio. To date, regional groundwater flow patterns have not been extensively studied which couple topography-controlled and recharge-controlled water tables in areas with contrasting climate, geology and topography. This forms a knowledge gap in this area which warrants more investigation. Furthermore, at a continental scale, Gleeson et al. (2011) hinted that the pattern of water table ratio does not mirror any single variable in the water table ratio equation (Eq. 1). However, this does not explain how the pattern behaves at a regional scale. This explains the scantiness of studies which have tried to examine and map the distribution of water table ratio at regional and continental scales. Therefore, it is equally imperative to test the assumptions put forward by Haitjema and Mitchell-Bruker (2005) and Gleeson et al. (2011) in groundwater flow modeling by alternating the boundary conditions in areas with contrasting climatic conditions. One test case should be in a semi-arid area with presumably low hydraulic conductivity therefore assuming a topography-controlled water table. The other case study being a humid terrain with high hydraulic conductivity, presumably depicting a recharge-controlled water table because of high hydraulic conductivity on one hand but climatologically a topography-controlled water table on the other. This will particularly facilitate the evaluation of the behavior, organization and hierarchy of local, subregional and regional groundwater flow systems as compared to the conventional flow systems as hypothesized by Gleeson et al. (2011) and Haitjema and Mitchell-Bruker (2005). The flowing subsection presents the state of knowledge, conceptual and scientific contentions in groundwater flow modeling.

\section{State of knowledge, conceptual and scientific gaps in groundwater flow modeling}

Ever since Toth (1963), a specified-head top boundary condition has predominantly been used for representing the water table in groundwater flow modeling. This mainly assumed that the water table correlates the topography (Liang et al. 2012; Goderniaux et al. 2013; Wang et al. 2014; Bresciani et al. 2016). However, there are arguments that the ensuing results do not reflect the changes in hydraulic conductivity and basin geometry and cannot be easily compared (Liang et al. 2012). In addition, specifying the hydraulic head along the water table implies that recharge is an unimpeded result of the model, argued Sanford (2002), hence making this approach generally unfit for sustainability studies. Nevertheless, the water table configurations in the real basins are much more complicated than those from the synthetic Tothian basins. Therefore, oversimplifications are constantly being made, which have not been yielding realistic results. This has generally misrepresented the nested groundwater flow systems in most basins, and the ensuing results may not reflect the real field conditions, and thus unfit for decision-making processes (Bresciani et al. 2016). It is further argued that the water table does not always follow topography as discussed earlier on based on the two types of water tables. In some cases, water table and the surface topography appear poorly correlated in most groundwater basins (Haitjema and Mitchell-Bruker 2005; Gleeson et al. 2011; Liang et al. 2012). In addition, it was pointed out in previous studies (Desbarats et al. 2002) that the concept of the correlation between the water table and the topography may be valid locally but not universally, and sometimes water table and topography mimic each other under undisturbed systems (Haitjema and Mitchell-Bruker 2005), which is a rare case since most groundwater basins have been developed for groundwater exploitation. Therefore, in order for the water table to rise to the highest point in a basin, the ratio of recharge over hydraulic conductivity must be greater than 0.2 (Mitchell-Bruker 1993; Liang et al. 2012). This can only happen when the low-permeable basin is overlain by a layer with even higher permeability such as sand and gravel. To that effect, groundwater flow modeling using real field case studies is still needed to empirically justify the findings based on synthetic Tothian basins and Toth's groundwater flow theories.

Having discussed the limitations of specified-head top boundary condition in groundwater flow modeling, the flux upper boundary is deemed the best approach in groundwater flow systems modeling. This enables simulation of complex natural conditions (e.g., climate change) (Liang et al. 2012). Equally so, the combination of recharge and hydraulic conductivity on the development of nested groundwater flow systems is equally an excellent approach for assessing basin-wide groundwater flow systems added (Liang et al. 2012). Moreover, the flux upper boundary is preferable for numerical simulation when examining how the flow patterns are affected by changes in infiltration, hydraulic conductivity or basin geometry (Liang et al. 2012). However, there is a caveat in this approach since it is based on isotropic media and limited geometric conditions. Further, it should be known that recharge is also dynamic, influenced by such factors as precipitation, surface temperature changes and land cover dynamics in the recharge zones/areas. This is a gray research area too, especially predicting the fate of organization and hierarchy of groundwater flow systems under future climate and land cover change scenarios.

In addition, numerical models that represent a flow system for a site with complex hydrogeologic conditions, such as a system with multilayered aquifers with different flow directions due to different aquifer stresses, strong upward or 
downward hydraulic gradients, are scanty too (Gao 2011). This argument is supported by Gassiat et al. (2013), who recited that the role of layered aquifer systems which are common in both consolidated and unconsolidated sediments has not been systematically explored in groundwater flow modeling. The identification of the volumes occupied by different orders of flow systems in 3D is yet another prime area of research in the field of basin-scale groundwater flow systems modeling (Wang et al. 2016, 2017). Two-dimensional rather than three-dimensional models have mostly been preferred because of the high computational demands of 3D models. Thus, regional groundwater flow systems have been studied and verified using simplified, 2D cross-sectional basin models (Jiang et al. 2011a, b; Wang et al. 2011; Zlotnik et al. 2011). Consequently, most modeling studies of regional groundwater flow have used simplifying assumptions of two-dimensional flow within a cross section and have neglected the impacts of human activities like pumping on regional groundwater flow. This argument dates back in the days of Freeze and Witherspoon (1967) and Toth (1963). However, with the rapid increase in computing power and availability of user-friendly, open-source modeling software, it is now possible to simulate large-scale regional groundwater flow systems in three dimensions (Zhou and Li 2011). Moreover, it is ostensibly apparent that different approaches of representing a flow domain in the model may yield different solutions to a problem (Gao 2011). These approaches may involve different ways of vertical discretization, different ways of representation of the various hydraulic units, or ways in which the boundary conditions are represented.

\section{Conclusions and future research direction based on the observed theoretical, scientific and conceptual contentions}

\section{Conclusion}

The literature provides hefty details on advances made in groundwater flow systems modeling. It reveals that numerous advances in the understanding of organization, pattern and hierarchy of groundwater flow systems have been made in so many parts of the world, using both the real field test cases and synthetic basins using 2D as well as at a limited scale in 3D models.

The state of knowledge and application of groundwater flow theories and models for groundwater sustainability assessment is reasonably rich, but there are still significant scientific, theoretical and conceptual as well as knowledge gaps and contentions. The use of synthetic Tothian basins, for example, dominates the literature despite decades of the existence of the theories. However, in spite of the observed theoretical and conceptual contentions, groundwater flow models developed using hypothetical basins and parameters have somehow raised the understanding of groundwater flow systems and theories. Nonetheless, an intuitive understanding of the real field problems is missing in the previous applications of the Tothian theories, especially so in the developing countries where applications are very limited.

A good understanding of groundwater flow systems is imperative for well siting, the choice of drilling technology, cost estimation and gathering prior water quality information. Moreover, essential scientific problems and policyrelated issues need improved datasets of local, regional and global hydrogeologic parameters and a better understanding of groundwater systems at regional to continental scales (Gleeson et al. 2014).

Groundwater flow systems have mostly been studied under restricted and hypothetical modeling conditions and assumptions. However, the application of groundwater flow systems modeling and the understanding of the hierarchy, pattern and organization of nested groundwater flow systems can still add more value and play a significant role in augmenting various efforts towards sustainable groundwater management in areas where groundwater is the sole and dependable source of water for various uses. Generally, numerical groundwater models have the potential of simulating three-dimensional groundwater flow in heterogeneous and anisotropic groundwater basins, but its applicability is very limited since most of the studies aim at analyzing the effects of a Tothian flow field and not heterogeneity in hydraulic conductivity as reported by Cardenas (2007). Cardenas and Jiang (2010) opined that groundwater flow geometries tend to be scale invariant, and therefore, this behavior has huge implications in regional, subregional and local flow systems.

It has been realized that recharge and hydraulic conductivity are not the only parameters which determine the difference between topography-controlled and recharge-controlled water tables. As hinted Haitjema and Mitchell-Bruker (2005) and Gleeson et al. (2011) that, aquifer thickness and distance between hydrological boundaries are equally important. However, the idea on the degree of importance of those parameters and under which geological/hydrogeologic and climatic conditions do they become prominent remains both a theoretical and knowledge gap (Hill et al. 2013). Further to that, Gleeson et al. (2011) opined that topography-controlled water tables that are found in mountainous terrains have limited regional groundwater flow $(\sim 10 \%)$. However, there is a huge scientific silence in the literature on whether this implies that topography-controlled water tables in subdued topography have prominent regional groundwater flow.

Calculations based on the Dupuit-Forchheimer assumptions compare favorably with those based on more rigorous methods when the slope of the free surface is small and when the depth of the unconfined flow field is shallow. 
However, the biggest knowledge gap in the Dupuit-Forchheimer theory lies in its limited application in confined, anisotropic and heterogeneous aquifer systems. Furthermore, the contemporary interpretation of the Dupuit-Forchheimer approximation allows for the vertical flow component, but the theory and its underlying assumptions remain the same. It is high time now to reinvestigate the validity of the theory and how it could be improved to accommodate the new theoretical and conceptual perspectives. This has to be combined with its rule of thumb that the Dupuit-Forchheimer approximation is acceptable where the distance between hydrological boundaries is five times larger than the aquifer thickness.

\section{Future research direction pertaining to the observed theoretical, scientific and conceptual contentions in understanding and conceptualization of groundwater flow systems}

More studies which seek to provide scientific explanation and proof on the presence of distinguishable nested groundwater flow systems and water table types in basins with contrasting climatic and geologic attributes are still needed. Equally important, mapping the distribution of water tables will enable characterization of regional flow systems as remarked by Gleeson et al. (2011). Moreover, recategorization of aquifers into usable and non-usable types and therefore defining a locally consistent scale of analysis for distinguishing topography-controlled and recharge-controlled water tables in all geologic, hydrogeologic and climatic settings is another area of future research. Further to that, future studies on regional groundwater flow modeling have to consider the conceptualization and understanding of water table types, which is critical for an in-depth understanding of regional groundwater flow systems in basins with varying geology and climate. More scientific work on how the classification and distribution of water table types is understood despite some insights from Haitjema and MitchellBruker (2005), Gleeson and Manning (2008) and Gleeson et al. (2011) remains yet another area of further research albeit the knowledge on where exactly recharge-controlled and topography-controlled water tables are found remains unclear and hazy, and thus open for further investigation.

Modeling the influence of future climate change and the dynamics of land covers on the organization, distribution, pattern and distortion of nested groundwater flow systems in basins with diverse hydrologic, hydrogeologic, climatic and topographic features is another research area requiring more scientific attention. Moreover, it is equally important to assess how groundwater in heterogeneous and anisotropic settings responds to groundwater stresses like varying recharge, land cover changes and groundwater pumping. This will help to understand the extent at which groundwater flow system hierarchy and organization may change, and examine the possible consequences on groundwater-related shallow surface water bodies in a basin through site-specific groundwater flow models.

While globally, little has been done on how the flow systems would behave if heterogeneous and anisotropic conditions on multilayered aquifer systems are assumed, even in homogenous and isotropic conditions, limited knowledge, and thus studies on the application of numerical models for characterizing the hierarchy, organization and distribution of groundwater flow systems with respect to topography-controlled and recharge-controlled water tables are still needed.

In order to be able to predict local and regional impacts of natural and human impacts on groundwater systems, it is imperative to add up to the advances made globally on regional groundwater flow systems modeling. Therefore, site-specific groundwater flow models are required to simulate impacts of human activities on groundwater flow systems in order to enhance the formulation of succinct, scientifically sound and sustainable groundwater resources development and management scenarios. More research is equally needed to establish the difference in equipotential fields between recharge-controlled water table and topography-controlled water table basins, taking into account contrasting geology and climate of different environments. Lastly, the demonstration of the Dupuit-Forchheimer approximation in areas with topography-controlled water tables will qualify/refute the tenets put forward by Haitjema and Mitchell-Bruker (2005) and that the approximation is acceptable in areas with usable aquifers, which literally are recharge-controlled water table areas.

Acknowledgements The authors wish to acknowledge the support of Water, Infrastructure and Sustainable Energy Futures (WISE FUTURES) Centre of Excellence based at the Nelson Mandela African Institution of Science and Technology (NM-AIST), Arusha-Tanzania for the scholarship which catered for tuition fees, accommodation, meals and partial research support. Moreover, we wish to acknowledge the support from my employer, specifically the Department of Geography and Environmental Studies at the Sokoine University of Agriculture for shouldering part of my research work through purchase of instruments and partial financial support to cater for field activities. The authors also wish to acknowledge the contribution of the late Prof. Alfred N.N. Muzuka in this manuscript. Unfortunately, he could not live to see this work published. We will cherish his contributions in this work and in the academic world at large. May his good soul continue to rest in eternal peace.

Funding The research work from which this manuscript has been developed has been funded by the Water, Infrastructure and Sustainable Energy Futures (WISE FUTURES) Centre of Excellence based at the Nelson Mandela African Institution of Science and Technology (NM-AIST), Arusha-Tanzania. 


\section{Compliance with ethical standards}

Conflict of interest Authors declare no conflict of interest with any organization which may impart bias of any kind in this manuscript.

Open Access This article is licensed under a Creative Commons Attribution 4.0 International License, which permits use, sharing, adaptation, distribution and reproduction in any medium or format, as long as you give appropriate credit to the original author(s) and the source, provide a link to the Creative Commons licence, and indicate if changes were made. The images or other third party material in this article are included in the article's Creative Commons licence, unless indicated otherwise in a credit line to the material. If material is not included in the article's Creative Commons licence and your intended use is not permitted by statutory regulation or exceeds the permitted use, you will need to obtain permission directly from the copyright holder. To view a copy of this licence, visit http://creativecommons.org/licenses/by/4.0/.

\section{References}

Ahmaruzzaman M, Gupta VK (2011) Rice husk and its ash as lowcost adsorbents in water and wastewater treatment. Ind Eng Chem Res 50(24):13589-13613. https://doi.org/10.1021/ie201 $477 \mathrm{c}$

Bresciani E, Gleeson T, Goderniaux P, de Dreuzy JR, Werner AD, Wörman A, Zijl W, Batelaan O (2016) Groundwater flow systems theory: research challenges beyond the specified-head top boundary condition. Hydrogeol J 24:1087-1090. https://doi. org/10.1007/s10040-016-1397-8

Cardenas MB (2007) Potential contribution of topography-driven regional groundwater flow to fractal stream chemistry: residence time distribution analysis of Toth flow. Geophys Res Lett 34:15. https://doi.org/10.1029/2006GL029126

Cardenas MB, Jiang XW (2010) Groundwater flow, transport, and residence times through topography-driven basins with exponentially decreasing permeability and porosity. Water Resour Res 46:W11538. https://doi.org/10.1029/2010WR009370

Desbarats AJ, Logan CE, Hinton MJ, Sharpe DR (2002) On the kriging of water table elevations using collateral information from a digital elevation model. J Hydrol 255(1):25-39

Dupuit J (1863) Theoretical and practical studies on the movement of water in open channels and through permeable ground, 2nd edn. Dunod, Paris

Forchheimer P (1886) Uber die Ergiebig keit von Brunnen-Anlogen und Siekersehlitzen. Zeitschrift des Architectenund Ingenieurs Vereins Zu Hunnover 32:539-564

Forchheimer P (1930) Hydraulik, 3rd edn. Teubner, Leipzig-Berlin

Freeze RA, Witherspoon PA (1966) Theoretical analysis of regional groundwater flow: analytical and numerical solutions to the mathematical model. Water Resour Res 2(4):641-656

Freeze RA, Witherspoon PA (1967) Theoretical analysis of regional groundwater flow: effect of water table configuration and subsurface permeability variation. Water Resour Res 4(3):581-590

Gao H (2011) Groundwater modeling for flow systems with complex geological and hydrogeological conditions. Proced Earth Planet Sci 3(2011):23-28. https://doi.org/10.1016/j.proeps.2011.09.061

Gassiat C, Gleeson T, Luijendijk E (2013) The location of old groundwater in hydrogeologic basins and layered aquifer systems. Geophys Res Lett 40(12):3042-3047. https://doi. org/10.1002/grl.50599

Gleeson T, Manning AH (2008) Regional groundwater flow in mountainous terrain: three-dimensional simulations of topographic and hydrogeologic controls. Water Resour Res 44:W10403. https://doi.org/10.1029/2008WR006848

Gleeson T, Marklund L, Smith L, Manning AH (2011) Classifying the water table at regional to continental scales. Geophys Res Lett 38:1-6. https://doi.org/10.1029/2010GL046427

Gleeson T, Moosdorf N, van Hartmann Beek LPHJ (2014) A glimpse beneath Earth's surface: GLobal HYdrogeologyMaPS (GLHYMPS) of permeability and porosity. Geophys Res Lett 41:3891-3898

Goderniaux P, Davy P, Bresciani E, de Dreuzy JR, Le Borgne T (2013) Partitioning a regional groundwater flow system into shallow local and deep regional flow compartments. Water Resour Res 49:2274-2286. https://doi.org/10.1002/wrcr.20186

Gupta VK, Saleh TA (2013) Sorption of pollutants by porous carbon, carbon nanotubes and fullerene-an overview. Environ Sci Pollut Res 20(5):2828-2843. https://doi.org/10.1007/s11356-013-1524-1

Haitjema HM, Mitchell-Bruker S (2005) Are water tables a subdued replica of the topography? Groundwater 43(6):781-786

Havril T, Toth A, Molson JW, Galsa Aw Mádl-Szonyi J (2017) Impacts of predicted climate change on groundwater flow systems: can wetlands disappear due to recharge reduction? J Hydrol. https://doi.org/10.1016/j.jhydrol.2017.09.020

Hill MC, Faunt CC, Belcher WR, Sweetkind DS, Tiedeman CR, Kavetski D (2013) Knowledge, transparency, and refutability in groundwater models, an example from the Death Valley regional groundwater flow system. Phys Chem Earth 64:105-116. https ://doi.org/10.1016/j.pce.2013.03.006

Hubbert MK (1940) The theory of ground-water motion. Trans Am Geophys Union 21(2):648. https://doi.org/10.1029/tr021i002p 00648-1

Huizar-Alvarez R, Ouysse S, Espinoza-Jaramillo MM, CarrilloRivera JJ, Mendoza-Archundia E (2016) The effects of water use on Tothian flow systems in the Mexico City conurbation determined from the geochemical and isotopic characteristics of groundwater. Environ Earth Sci. https://doi.org/10.1007/s1266 5-016-5843-7

Jiang XW, Wan L, Cardenas MB, Ge S, Wang X-S (2011a) Simultaneous rejuvenation and aging of groundwater in basins due to depthdecaying hydraulic conductivity and porosity. Geophys Res Lett 37:L05403. https://doi.org/10.1029/2010GL042387

Jiang XW, Wang XS, Wan L, Ge S (2011b) An analytical study on stagnation points in nested flow systems in basins with depthdecaying hydraulic conductivity. Water Resour Res 47(1):W01512

Kurylyk BL, MacQuarrie KTB, Caissie D, McKenzie JM (2015) Shallow groundwater thermal sensitivity to climate change and land cover disturbances: derivation of analytical expressions and implications for stream temperature modeling. Hydrol Earth Syst Sci 19(5):2469-2489. https://doi.org/10.5194/hess-19-2469-2015

Liang X, Quan D, Jin M, Liu Y, Zhang R (2012) Numerical simulation of groundwater flow patterns using flux as upper boundary. Hydrol Process. https://doi.org/10.1002/hyp.9477

Mitchell-Bruker S (1993) Modeling steady state groundwater flow and surface water interactions. Ph.D. diss., School of Public and Environmental Affairs, Indiana University

Saleh TA, Gupta VK (2014) Processing methods, characteristics and adsorption behavior of tire derived carbons: a review. Adv Colloid Interface Sci 211(2014):92-100. https://doi.org/10.1016/j. cis.2014.06.006

Sanford WE (2002) Recharge and groundwater models: an overview. Hydrogeol J 10(1):110-120. https://doi.org/10.1007/s1004 $0-001-0173-5$

Toth J (1962) A theory of groundwater motion in small drainage basins in Central Alberta. J Geophys Res 67(11):4375-4387

Toth J (1963) A theoretical analysis of groundwater flow in small drainage basins. J Geophys Res 68(16):4795-4812

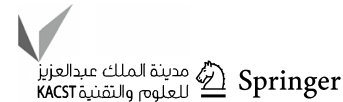


Vandenberg A (1980) Regional groundwater motion in response to an oscillating water table. J Hydrol 47:333-348

Wang XS, Jiang XW, Wan L, Ge S, Li H (2011) A new analytical solution of topography-driven flow in a drainage basin with depth-dependent anisotropy of permeability. Water Resour Res 47:W09603. https://doi.org/10.1029/2011WR010507

Wang JZ, Jiang XW, Wan L, Wang XS, Li H (2014) An analytical study on groundwater flow in drainage basins with horizontal wells. Hydrogeol J 22(7):1625-1638

Wang H, Jiang XW, Wan L, Han G, Guo H (2015) Hydrogeochemical characterization of groundwater flow systems in the discharge area of a river basin. J Hydrol 527:433-441

Wang J, Wörman A, Bresciani E, Wan L, Wang X, Jiang X (2016) On the use of late-time peaks of residence time distributions for the characterization of hierarchically nested groundwater flow systems. J Hydrol 543:47-58. https://doi.org/10.1016/j.jhydr ol.2016.04.034

Wang XS, Wan L, Jiang XW, Li H, Zhou Y, Wang J, Ji X (2017) Identifying three-dimensional nested groundwater flow systems in a Tóthian basin. Adv Water Resour 108:139-156. https://doi. org/10.1016/j.advwatres.2017.07.016

Welch LA, Allen DM (2012) Consistency of groundwater flow patterns in mountainous topography: implications for valley bottom water replenishment and for defining groundwater flow boundaries.
Water Resour Res 48:W05526. https://doi.org/10.1029/2011W R010901

Worman A, Packman AI, Marklund L, HarveyStone JWSH (2007) Fractal topography and subsurface water flows from fluvial bedforms to the continental shield. Geophys Res Lett 34:L07402. https://doi.org/10.1029/2007GL029426

Zhou Y, Li W (2011) A review of regional groundwater fow modeling. Geosci Front 2(2):205-214. https://doi.org/10.1016/j. gsf.2011.03.003

Zhao K-Y, Jiang X-W, Wang X-S, Wan L, Wang J-Z, Wang H, Li H (2018) An analytical study on nested flow systems in a Tóthian basin with a periodically changing water table. J Hydrol 556:813823. https://doi.org/10.1016/j.jhydrol.2016.09.051

Zlotnik VA, Cardenas MB, Toundykov D (2011) Effects of multiscale anisotropy on bas in and hyporheic groundwater flow. GroundWater 49(4):576-583. https://doi.org/10.111 $1 /$ j.1745-6584.2010.00775.x

Publisher's Note Springer Nature remains neutral with regard to jurisdictional claims in published maps and institutional affiliations. 